\title{
OBITUARY
}

\section{ALEKSANDR ALEKSEEVICH LEBEDEV}

Aleksandr Alekseevich Lebedev, an outstanding Soviet physicist, Hero of Socialist Labor, and Academician, passed away on March 15, 1969. A. A. Lebedev was born in Ponevezh on November $27,1893$. In 1916 , he graduated from the physics and mathematics department of St. Petersburg University, and was retained at that university to complete his preparation for his scientific calling. He worked at the same time as a laboratory technician at the State Glass Plant. Academician D. S. Rozhdestvenskii drew A. A. Lebedev into research work on the development of the Soviet optical and optical glass industry. After the organization of the State Optical Institute in 1919, A. A. Lebedev became part of the staff of that institute and continued in that capacity until the end of his life, tracing a path from staff colleague to head of the laboratory and of the science division. All of the principal works accomplished by Aleksandr Alekseevich were completed at that institute.

Aleksandr Alekseevich developed the theory of the vitreous state of matter, and devised scientifically valid methods of annealing optical glass on the basis of that theory. In the course of an exchange assignment to the laboratory of Professor W. Bragg in London, he was the first to use a magnetic lens for focusing beams of electrons diffracted on a crystal (1930-1931), and became one of the pioneers of electron optics.

A. A. Lebedev proposed coating thin films on glass parts and thereby minimizing light reflection losses. Following out this idea, Academician I. V. Grebenshchikov later worked out a procedure for brightening instrument optics. The industry of the Soviet Union was the pacesetter in the world in making use of this highly us eful operation. In the development of the interference microscope, in the development of a new method for comparing the meter standard with a light wavelength, and in the development of a wideaperture high-frequency interference type light modulator, Aleksandr Alekseevich distinguished himself as a scientist with a profound understanding of light interference phenomena.

The world's first optical-radar geodesic range finder, the Soviet models of electron microscopes, instruments for investigating the structure of matter by the electron diffraction method and by $x-r a y$ spectral analysis methods, and many other unique physics researcn instruments, were designed and developed under the supervision of A. A. Lebedev. He also supervised programs of research on the physics of the atmosphere and on spectroscopy in the infrared region of the spectrum.

His probing analytical mind, brilliant scientific intuition, and his command of skills in setting up and carrying out experiments are the salient traits of the creativity of Aleksandr Alekseevich.

A. A. Lebedev's legacy includes numerous schools of physicists at the S. I. Vavilov State Optical Institute, and at the A. A. Zhdanov Leningrad State University, where he headed the department of electrophysics, in the Scientific-Research Institute which he founded in Moscow, and in many other industrial and research organizations.

In 1939, A. A. Lebedev was elected Corresponding Member of the Academy of Sciences of the USSR, and in 1943 he was elected a full member of the Academy. In 1946, he was elected a full member of the Academy of Artillery Sciences. In the years 1949-1957, he served as assistant secretary Academician of the branch of physical and mathematical sciences of the Academy of Sciences of the USSR. Aleksandr Alekseevich was awarded two State Prizes, and was awarded the Lenin Prize in 1959.

The public and official activities of Aleksandr Alekseevich were also many-sided. During the years of the Great Patriotic War he served as assistant to the authorized representative (then $S$. I. Vavilov) of the State Defense Committee. In 1950, he was elected to the post of Deputy of the Supreme Soviet of the

Translated from Zhurnal Prikladnoi Spektroskopii, Vol. 10, No. 5, pp. 883-884, May, 1969.

- 1972 Consultants Bureau, a division of Plenum Publishing Corporation, 227 West 17th Street, New York, N.Y. 10011. All rights reserved. This article cannot be reproduced for any purpose whatsoever without permission of the publisher. A copy of this article is available from the publisher for $\$ 15.00$. 
USSR, and in 1954 he was reelected Deputy of the Supreme Soviet of the USSR and also elected to the post of vice-chairman of the Soviet of the Union.

The title of Hero of Socialist Labor, four Orders of Lenin, three Orders of the Labor Red Banner, the "Badge of Honor" order, and various medals mark the occasions when the party and the government took official notice of the great services rendered by Aleksandr Alekseevich Lebedev to the homeland. 